\title{
MODALIDADES DE PARTICIPAÇÃO POLÍTICA EM WEBSITES ELEITORAIS: UMA ANÁLISE DE FÓRUNS DE DISCUSSÃO COM UMA PROPOSTA METODOLÓGICA
}

Sylvia Iasulaitis

\section{Resumo}

O objetivo neste artigo é analisar os fóruns de discussão para debate de propostas de governo durante o pleito presidencial brasileiro de 2010 , com o intuito de averiguar a lógica dos candidatos na utilização destas ferramentas, o nível de controle e o teor das trocas discursivas. O modelo apresentado consiste em uma proposta metodológica para análise de fóruns de discussão em campanhas eleitorais, com base em sete dimensões: avaliação dos constrangimentos e incentivos à participação, inclusividade, reciprocidade, respeito mútuo, identificação, grau de heterogeneidade e tematização e conteúdo. Conclui-se que os candidatos se atentaram para o fato de que é estratégico se beneficiar da nova arquitetura de participação da Web 2.0 e da inteligência coletiva, mas o modelo de campanha permanece sendo top-down, com um controle firme e centralizado.

Palavras-chaves: Internet; Participação Política; Fóruns Eletrônicos; Websites Eleitorais; Estratégias de Investigação.

\begin{abstract}
The aim of this paper is to analyze the forums for discussion of proposals for government during the 2010 Brazilian presidential elections, in order to ascertain the logic of the candidates in using these tools, the level of control and the discursive content of the exchanges carried out. The model consists of a methodology for analysis of discussion forums on electoral campaigns, based on seven dimensions: the assessment of constraints and incentives for participation, inclusiveness, reciprocity, mutual respect, identification, heterogeneity and theme selection and content. We conclude that the candidates paid attention to the fact that is of strategic benefit of the new architecture of participation of Web 2.0 and collective intelligence, but the campaign template remains top-down, with a firm and centralized control.
\end{abstract}

Keywords: Internet; Political Participation; Electronic Forums; Campaign Websites; Strategies Research.

\section{Introdução}

Gradativamente, os partidos políticos e candidatos estão fazendo uso de uma variedade de ferramentas de comunicação eletrônica em suas campanhas eleitorais. O rápido crescimento do uso da Internet em campanhas nas democracias ocidentais durante as últimas décadas tem provocado muita especulação sobre suas implicações sociais e, particularmente, políticas. 
É neste sentido que estão sendo desenvolvidas interessantes análises sobre as aplicações que partidos políticos e candidatos têm feito das Novas Tecnologias de Informação e Comunicação. No entanto, a maior parte desta produção, basicamente anglo-saxã, tem enfocado em uma estratégia descritiva dos conteúdos dos websites políticos, cujo intuito é mapear seus recursos e funções.

A estratégia metodológica mais comumente empregada é a análise de conteúdo de websites políticos que, embora tenha assumido uma diversidade de adaptações, segue a proposta de investigação desenvolvida por Gibson e Ward em um seminal artigo em 2000. Nestes estudos aplicam-se diversas variáveis dicotômicas, que indicam a presença ou ausência de vários elementos estruturais, que dão preciosas pistas a respeito das estratégias, objetivos e nível de profissionalismo dos websites (GIBSON e WARD, 2002; CARLSON e DJUPSUND, 2001; NEWELL, 2001; NORRIS, 2003; SCHWEITZER, 2005).

A Internet, no entanto, é ainda um meio relativamente novo e seu uso em processos eleitorais trata-se de um fenômeno em rápida evolução. É neste sentido que novas estratégias metodológicas são imperiosas para responder às novas perguntas de pesquisa. $\mathrm{Na}$ atual fase, corroborando autores como Schneider e Foot (2004), Sudweeks e Simoff (1999), Howard (2002), dentre outros, as abordagens para a pesquisa no campo de estudos sobre Internet e Política não são necessariamente mutuamente excludentes; a Internet é um objeto de pesquisa que possibilita a reconciliação de princípios quantitativos e qualitativos.

Embora seja importante identificar se as ferramentas interativas estão presentes em websites partidários e eleitorais, não menos relevante é analisar a forma de utilização das mesmas. Ao se categorizar um website político a partir da existência ou não de ferramentas interativas, como fóruns de discussão e chats, não responde-se aos problemas de pesquisa referentes à forma de controle destes espaços pelos partidos, ao teor das trocas discursivas neles realizadas, tampouco quanto à qualidade democrática de tais espaços. Isto porque a presença de ferramentas interativas em websites eleitorais não garante a existência de efetiva interação entre eleitores e candidatos ou de eleitores entre si.

Conforme assinala Frau-Meigs (2001 apud DADER e CHENG, 2011) convém não confundir interatividade com interação, já que uma coisa é o fato dos cidadãos permutarem recursos com uma equipe impessoal por meio de ferramentas informáticas, e outra muito distinta é que se gere um verdadeiro intercâmbio de opiniões entre pessoas que deliberam sequencialmente por intermédio de aplicativos cibernéticos.

Analisando os websites eleitorais dos candidatos à presidência no pleito brasileiro de 2010 e categorizando seus elementos estruturais no que se refere às formas de comunicação one-way (assimétricas), bidirecionais (simétricas), bem como de três vias - que envolve o contato de eleitores com candidatos e de eleitores entre si - , nossos achados de pesquisa revelaram 
que em poucos websites foram oferecidos dispositivos que possibilitavam trocas discursivas e um formato de comunicação de três vias. Dentre as parcas opções encontradas estavam os fóruns que possuíam o propósito de debater programas de governo disponibilizados nos websites eleitorais dos então presidenciáveis José Serra (PSDB) e Marina Silva (PV).

Considerando que a literatura temática levanta diversas hipóteses a respeito da qualidade democrática nestes novos formatos, no entanto é ainda permeada excessivamente por conjecturas e limitado conhecimento empírico, partimos para uma experimentação e análise do uso destas ferramentas, de modo a apreender o potencial democrático, possibilidades e limites de tais iniciativas.

\section{Perguntas de pesquisa}

O objetivo foi investigar se e de que forma o potencial interativo da Internet foi empregado por partidos e candidatos durante a campanha presidencial em 2010 e se e em que medida as ferramentas interativas em websites eleitorais foram utilizadas para aumentar a qualidade do debate democrático e estreitar os laços com o eleitorado durante a campanha política.

Considerando que espaços de conversação civil online como fóruns para debater propostas de governo, ao menos em tese, encetam oportunidade para que cidadãos comuns dialoguem entre si, se posicionem a respeito de temas e demandas e interpelem candidatos sobre suas propostas, os mesmos tornam-se de particular interesse para investigações empíricas. É neste sentido que buscamos compreender como tais ferramentas foram efetivamente utilizadas e se representaram ou não melhoria para a qualidade democrática. As seguintes perguntas de pesquisa orientaram nossa análise:

1. Em que medida os comunicadores políticos estão incentivando a interação e a participação do público nos websites eleitorais? É possível identificar constrangimentos e incentivos que o gerenciamento dos fóruns online e o processo de moderação empreendido por parte do staff da campanha exerce sobre os participantes?

2. Os fóruns cumpriram de fato os propósitos de debater programa de governo e aproximar candidatos e cidadãos, possibilitando aos primeiros fazer seu conteúdo programático conhecido e debatido e aos últimos realizar inputs ao sistema político, comunicar seus anseios e demandas? Ou, pelo contrário, constituiram-se como fóruns de reforço de campanha para os já convertidos, onde verificou-se uma babel de vozes a proferir ofensas contra os adversários?

3. Qual a forma e conteúdo das trocas discursivas realizadas nos fóruns de discussão em websites de campanha? Em tais dispositivos seguem- 
se os princípios de participação democrática, ou seja, são inclusivos, apresentam diversidade de opiniões, reciprocidade e respeito mútuo? As discussões são marcadas pela civilidade? Em que medida participam (ou não) da construção da comunicação consensual e quais são seus objetivos?

\section{Discussão teórica}

As assertivas sobre as potencialidades e os efeitos da relação entre democracia e novas tecnologias, especialmente na década de 1990, eram demasiadamente extremistas: ou entusiasticamente exaltavam-se as possibilidades oferecidas pelas NTIC's ou, por outro lado, se enfatizavam os aspectos negativos da Internet, abordagens que Norris (2003) denomina de ciberotimistas e cibercéticas.

Tão logo a Internet passou a ser empregada com propósitos políticos, autores de uma vertente mais ciberotimista apontaram que a adoção de Novas Tecnologias de Informação e Comunicação poderia diminuir a lacuna existente entre cidadãos e políticos, fortalecer o vínculo da cidadania com os candidatos e melhorar o nível de informação política dos eleitores (CORRADO e FIRESTONE apud ANDUIZA, 2009).

Nesta perspectiva, a utilização destas ferramentas durante as eleições pode beneficiar o processo democrático "incluyendo más gente corriente en los procesos de formación de opinión política y de toma de decisiones" (LANDTSHEER, KRASNOBOKAe NEUNER, 2001). A participação do candidato ou líder político em salas de bate-papo e fóruns de discussão com quantas pessoas queiram interpelá-lo pode gerar uma corrente de simpatia e curiosidade com eco midiático multiplicador (LANDTSHEER, KRASNOBOKA e NEUNER, 2001).

Dispositivos como fóruns de discussão poderiam instaurar formas de comunicação bottom-up (de baixo para cima), uma vez que ao internauta seria possibilitado expressar suas preocupações e demandas, questionar os agentes políticos e candidatos, exprimir suas opiniões, o que poderia ampliar a influência dos cidadãos comuns na construção da agenda política e até mesmo na formulação de políticas públicas. De acordo com este posicionamento, este debate iniciado na campanha política poderia se perpetuar durante um possível mandato e influenciar nos outputs do sistema político.

Tais características interativas, teoricamente, possuiriam um potencial para ativar e mobilizar os cidadãos e fomentar sua participação. Por tais motivos, autores ciberotimistas avaliam a Internet com potencial de contribuir tanto para melhorar a qualidade da representação quanto para abrir novos canais de participação aos cidadãos e, portanto, revigorar a relação entre candidatos e cidadãos (BENTIVEGNA, 2001).

Muitos teóricos nesta primeira fase de estudos sobre Internet e Política visionavam os candidatos interagindo online diretamente com os eleitores e 
proporcionando discussão horizontal dos cidadãos entre si em seus websites. No entanto, a primeira onda de pesquisas empíricas demonstrou que, na prática, poucos fizeram isso nas campanhas internacionais analisadas, o que reforçou a visão de autores de uma linha mais cibercética, que acrescentaram que seria pouco provável que o fizessem num futuro próximo (DAVIS, 1999; MARGOLIS e RESNICK, 2000).

Apesar de serem amplamente enfatizadas justamente as ferramentas interativas da Internet, a falta de interatividade ${ }^{1}$ mostrou-se a deficiência mais significativa dos agentes políticos ao utilizarem a rede eletrônica em suas campanhas (GIBSON e WARD, 1998; KAMARCK, 2002; SADOW 2000). Analisando as possibilidades de comunicação bidirecional ou de três vias em websites eleitorais, Ward (2008) enfatiza que muitos estudos indicam que os partidos vêm mostrando-se desconfiados em relação à interatividade, temendo que a abertura de suas páginas permita a seus oponentes atacá-los, fazendo-os perder o controle da agenda de campanha.

Para investigadores como Richard Davis (1999), a interação online expõe o discurso de campanha a uma forma de escrutínio geralmente indesejado. Infere-se que a razão principal dos candidatos subestimarem a interatividade em seus websites é o receio de perder o controle e tornar as páginas vulneráveis a conteúdos "impróprios" e também demandar dispêndio de muito tempo, por exemplo, para responder mensagens. Assim, na imensa maioria das campanhas virtuais realizadas até a entrada do novo milênio a interação direta entre candidato e público foi evitada (STROMER-GALLEY, 2000).

A importância da interatividade, de um ponto de vista democrático, não é provável nos interesses de grande parte das campanhas. Portanto, se não há espaços significativos para a interação é porque esta é interpretada como um risco para o controle estratégico da campanha por parte do partido, mais do que como uma oportunidade para a participação das bases. 0 debate pode trazer à tona diferenças internas e conflitos que os partidos não estão dispostos a assumir (VACCARI, 2008).

Este conjunto de investigadores relatou que os candidatos preferiam um website bem elaborado, com materiais e notícias bem escritas, anúncios de eventos e pesquisas de opinião, de forma que eles tivessem controle sobre as mensagens (STROMER-GALLEY, 2000). Portanto, os candidatos continuariam a utilizar a Internet como um meio de promover suas campanhas e para angariar fundos, mais do que como um fórum para debater com os cidadãos (DAVIS, 1999). Neste sentido, poderia se esperar que os websites partidários fossem mais fortes em sua função de informação de cima para baixo (top-down) do que como canais de comunicação de mão dupla (NORRIS, 2001).

1 O termo interatividade ressalta a participação ativa do beneficiário de uma transação de informação (LÉVY, 1999, p. 79), onde as formas monologais são substituídas pelas formas dialogais. 
Embora em um primeiro momento, em consonância com a fase Web 1.0, de fato os websites eleitorais tenham se assemelhado a panfletos eletrônicos, com uma ínfima utilização do potencial interativo da Internet, nota-se que atualmente alguns agentes políticos passaram a desenvolver suas campanhas na Internet para além da simples criação de websites, cujos conteúdos deixaram de ser a mera transposição do material offline para online. Alguns partidos e candidatos vêm procurando adaptar a lógica da Web 2.0 às suas campanhas e utilizar, ao menos em parte, suas ferramentas interativas, como fóruns de discussões, blogs, microblogs, como por exemplo o Twitter, redes sociais, bem como ferramentas que podem ser descritas como híbridas, e-newsletters, hospedagem de vídeos online no YouTube, etc.

A Web 2.0 pressupõe um uso diferenciado da Internet como uma plataforma participativa, cujos princípios são de tirar proveito da inteligência coletiva e promover uma ética de cooperação (O'REILLY e BATTELLE, 2009). Para a comunicação política, esta plataforma pressupõe mudanças e dentre as principais estão a passagem de um modelo de distribuição de mensagens one to many (de um a muitos) a outro many to many (de muitos a muitos) e a ampliação de canais de comunicação bottom-up, ou seja, de baixo para cima (GIBSON e RÖMMELE, 2007). Por outro lado, facilita a organização de um ativismo online, propondo aos simpatizantes distintas atividades em função de seus interesses e disponibilidades. Trata-se de ativar seletivamente aqueles que, por sua vez, podem mobilizar outros eleitores (ANDUIZA, 2009).

\section{Metodologia e estratégias de investigação}

A utilização de ferramentas interativas por partidos e candidatos em seus websites eleitorais trata-se de um fenômeno recente e praticamente não se verificam análises específicas de fóruns de discussão de websites de campanha. Tal cenário representou um desafio metodológico. Nesta investigação não interessou apenas registrar a existência ou não de fóruns nas páginas dos candidatos, mas, sobretudo, analisar a lógica do partido e da coligação na utilização desta ferramenta, sua forma e conteúdo, o nível de controle e o teor das trocas discursivas ali permitidas. Objetivou-se, ainda, investigar as formas de interação entre os produtores e os usuários e a natureza das propostas que resultaram desta interação.

O exame das práticas comunicacionais neste nível de análise representa um grande desafio metodológico, visto que somente é possível fazer afirmações categóricas a respeito da arquitetura de participação ser democrática ou não mediante uma observação direta dos fóruns, a partir da experimentação do uso do dispositivo. Como afirma Velasco (2002), o trabalho de campo é a situação necessária para que o investigador seja copartícipe das experiências dos outros, a partir da introdução nos seus circuitos de comunicação e emaranhando-se em suas redes sociais.

Para os propósitos deste estudo, não bastava coletar os dados do fórum para uma posterior análise de conteúdo; considerando o caráter 
efêmero dos websites eleitorais devido à legislação eleitoral brasileira, com o agravante de que alguns fóruns foram pós-moderados, tornou-se imperiosa a participação frequente no interior dos mesmos, para captar rastros digitais da participação cidadã antes que os mesmos fossem eliminados.

A pesquisa nos ambientes interacionais da comunicação mediada pelo computador caracteriza-se pela ausência física dos pesquisadores, sendo possível tornar-se invisível (HINE, 2004), ver sem ser visto, ou seja, realizar algo como uma "observação não-participante", onde o pesquisador não interfere a princípio na dinâmica da interação observada.

Para os propósitos deste estudo, foi necessária uma composição de técnicas que resultaram em um aparato metodológico específico, o que Becker (1993) denomina "multimétodo", com observação das interações mediadas pelo computador e a análise de conteúdo; portanto, uma junção de abordagens de cunho qualitativo e quantitativo. Analisamos os fóruns de discussão para debater programa de governo realizados nos websites eleitorais dos candidatos José Serra e Marina Silva, os quais previam a interação dos participantes entre si e com os representantes da campanha, administradores dos fóruns. Os objetos de estudos foram, portanto, ferramentas de comunicação assíncronas, ou seja, não realizadas em tempo real e tiveram um caráter semi-permanente (transitório) durante a campanha eleitoral de 2010.

Para análise e tratamento dos dados, procuramos transformar as principais hipóteses desenvolvidas na literatura em indicadores testáveis empiricamente. Por outro lado, nos referenciamos em uma literatura que analisa fóruns de debates sobre temas polêmicos, como aborto, publicidade infantil, feminismo e a comunidade Usenet (DAVIS, 1999; WITSCHGE, 2002; WOJCIK, 2008; GRÖNLUND et. al., 2007; SCHENEIDER, 1997; HERRING et. al., 2002), bem como nas pesquisas empíricas de avaliação da qualidade da deliberação online (STEENBERGEN et. al., 2003; DAHLBERG, 2001; BÄCHTIGER et. al., 2009; MANSBRIDGE et. al., 2010; STROMER-GALLEY, 2007; WALES et. al., 2010; SAMPAIO, MAIA e MARQUES, 2010; MENDONÇA e PEREIRA, 2011), sobretudo na proposta analítica Discourse Quality Index (DQI), suas variações e diversas aplicações.

Adaptando-se tais desenhos de pesquisa para o escopo e objeto deste estudo, o modelo apresentado consiste em um primeiro esforço metodológico para desenvolver uma análise dos fóruns de discussão estabelecidos na ambiência da Internet durante as campanhas eleitorais.

A avaliação da qualidade das discussões foi empreendida de acordo com sete dimensões de análise, que foram operacionalizadas com alguns indicadores, qualitativos e quantitativos, conforme explicitado na Tabela 1. 
Tabela 1 - Modelo de análise dos fóruns de discussão de programa de governo em websites eleitorais

\begin{tabular}{|c|c|c|}
\hline $\begin{array}{l}\text { Dimensão de } \\
\text { Análise }\end{array}$ & Indicador & Classificação \\
\hline $\begin{array}{l}\text { I. Constrangimentos e } \\
\text { incentivos à } \\
\text { participação }\end{array}$ & $\begin{array}{l}\text { Regras formais e papel da } \\
\text { moderação e gerenciamento } \\
\text { por parte do staff. }\end{array}$ & $\begin{array}{c}\text { Função do moderador do } \\
\text { fórum como Gestor, Árbitro } \\
\text { ou Mediador. }\end{array}$ \\
\hline $\begin{array}{l}\text { II. Inclusividade e } \\
\text { Diversidade da } \\
\text { Participação }\end{array}$ & $\begin{array}{l}\text { Número de mensagens } \\
\text { postadas e concentração de } \\
\text { posts por participante. }\end{array}$ & $\begin{array}{l}\text { One timer ou escala cardinal } \\
\text { ( } 2 \text { a } 5,6 \text { a } 10,11 \text { ou mais). }\end{array}$ \\
\hline $\begin{array}{l}\text { III. Reciprocidade do } \\
\text { debate }\end{array}$ & $\begin{array}{l}\text { Porcentagem de comentários } \\
\text { com base na apresentação de } \\
\text { marcas de reciprocidade. }\end{array}$ & Monológico ou Dialógico. \\
\hline IV. Respeito mútuo & $\begin{array}{l}\text { Nível de respeito ou } \\
\text { desrespeito (flames) e em } \\
\text { relação a quem, mediante o } \\
\text { uso de estereótipos e } \\
\text { descrições ofensivas. }\end{array}$ & $\begin{array}{c}\text { Respeitosa } \\
\text { Sem respeito: rude ou incivil } \\
\text { Desrespeito a: } \\
\text { moderadores, argumentos, } \\
\text { terceiros (indivíduos, } \\
\text { adversários), grupos ou } \\
\text { instituições. } \\
\end{array}$ \\
\hline V. Identificação & $\begin{array}{l}\text { Perfil do participante quanto à } \\
\text { auto-identificação ou } \\
\text { participação anônima. }\end{array}$ & Identificada, anônima. \\
\hline $\begin{array}{l}\text { VI. Grau de } \\
\text { Heterogeneidade }\end{array}$ & $\begin{array}{l}\text { Diversidade de opiniões, } \\
\text { argumentos e pontos de vista. }\end{array}$ & $\begin{array}{c}\text { Consensual ou } \\
\text { posicionamento crítico. } \\
\end{array}$ \\
\hline $\begin{array}{l}\text { VII. Tematização e } \\
\text { Conteúdo }\end{array}$ & $\begin{array}{l}\text { Categorização do conteúdo } \\
\text { dos posts. Mapeamento do } \\
\text { teor das mensagens postadas } \\
\text { nos fóruns. }\end{array}$ & $\begin{array}{c}\text { Campanha, Aclamação } \\
\text { Ataque a adversários. } \\
\text { Propostas ou comentários } \\
\text { para fomento ao programa } \\
\text { de governo. }\end{array}$ \\
\hline
\end{tabular}

Fonte: Autoria própria.

\section{Apresentação e análise dos dados}

De acordo com o balanço realizado pelas respectivas coordenações de campanha, até a data de fechamento do relatório analítico o fórum do candidato José Serra havia recebido 8.311 mensagens, ao passo que o fórum da candidata Marina Silva registrou 980 contribuições, as quais foram distribuídas por eixos temáticos.

O corpus empírico desta análise foi constituído por todas as mensagens postadas em dois fóruns temáticos de cada candidato até o final do primeiro turno da campanha eleitoral. Do website do candidato Serra foram selecionados os fóruns Social Democracia $(n=1053)$, por ser o fórum com o maior número de mensagens e cujos posts eram os mais populares (mais comentados) e o de Reforma Agrária $(n=67)$, por conter propostas de integrantes da coordenação de campanha. $O$ intuito aqui foi verificar se o perfil das mensagens era distinto nos fóruns onde havia participação direta de 
integrantes do staff. Quanto ao website de Marina Silva, seguindo o mesmo critério de selecionar o tema com o maior número de propostas, analisamos o fórum Educação para a sociedade do conhecimento $(n=163)$ e o segundo escolhido também por conter o maior número de comentários e respostas do staff da campanha foi o fórum Cultura e Fortalecimento da Diversidade $(n=42)$.

As principais características dos fóruns online serão comentadas nos próximos tópicos, que avaliam se e até que ponto os debates ocorreram de acordo com os ideais democráticos de participação.

\section{Constrangimentos e incentivos à participação nos fóruns online}

No quesito constrangimentos e incentivos à participação dos cidadãos, os fóruns foram analisados no intuito de identificar o perfil do gerenciamento por parte do staff da campanha, as regras formais e informais que regeram os debates online, os papéis dos moderadores (Gestor, Árbitro ou Mediador) e o nível de controle exercido pelos mesmos. Buscou-se verificar, ainda, se havia sensação ou evidência de censura no interior dos mesmos.

No que se refere às regras formais, o código de conduta do fórum do candidato José Serra exortava os participantes a cumprirem os preceitos básicos da conversa civilizada e advertia quanto à proibição de: fazer campanhas (fosse de candidaturas ou de causas), hostilizar adversários políticos e participantes, utilizar linguagem chula ou palavrões, fugir do tema e promover luta política. O código de conduta previa, ainda, a eliminação de conteúdos que não estivessem de acordo com os temas das áreas em que foram publicados, além da remoção de usuários reincidentes nas práticas contrárias às políticas de conteúdo e comunidade. Já o fórum de discussão sobre programa de governo de Marina Silva não tornou público um código de conduta.

Quanto ao processo de moderação, o fórum de Marina Silva foi moderado a priori, ou seja, era necessária a liberação do moderador para que a mensagem aparecesse no site; já o do candidato José Serra exigia um cadastro e era pós-moderado.

Analisando a literatura que trata da ação dos moderadores em fóruns de discussão online, é possível verificar que há uma diversidade de tipologias para classificá-los (WOJCIK, 2008; COLEMAN e GÖTZE, 2001; WHITE, 2000). A partir das categorizações propostas, adotamos uma tipologia simplificada e reclassificamos os papéis dos moderadores com base nos propósitos deste estudo, buscando identificar três principais funções do moderador: gestor, árbitro e mediador.

Nesta investigação, entendemos que o moderador no papel de gestor procede no sentido de organizar o fórum, propondo temas e questões, e conduz o debate especialmente atento quanto ao foco, cronogramas e lista de tarefas. O moderador quando atua como gestor procura manter os participantes no assunto ou classifica as mensagens de acordo com o tópico, 
pode cumprir também um papel de help desk oferecendo instruções técnicas aos participantes e pode, ainda, ser um especialista em um tema específico.

No exercício das funções de árbitro, o moderador controla o que é ou não publicado no fórum e a maneira ou forma que as mensagens estão autorizadas a ter. Neste caso, age como um gatekeeper, censurando ou removendo as mensagens que desrespeitem as regras do fórum, ao mesmo tempo encaminhando aos remetentes explicações sobre os conteúdos removidos, para que os mesmos possam readequar suas mensagens. O papel de árbitro é provavelmente o mais conhecido dos papéis dos moderadores, em que suas ações visam fazer com que os participantes respeitem as regras do debate. Neste estudo, consideramos que o árbitro pode basear sua ação mais em critérios técnicos (a partir de ação objetiva pautada em um código de conduta, por exemplo) ou ideológicos.

Finalmente, quando assume a função de mediador, o moderador atua no sentido de estimular o debate, toma atitudes quando os participantes entram em conflito, facilita o intercâmbio entre políticos e cidadãos comuns, na medida em que responde ou comenta questionamentos em nome do candidato e sistematiza os resultados da participação, ou seja, os dados, tópicos e contribuições que chegarão ao conhecimento do candidato e da coligação. Portanto, a mediação assume um vetor de sentido duplo, ou seja, do candidato para o internauta e do internauta para o candidato. Considerando que o moderador na condição de mediador é um intermediário entre o utilizador da Internet e o candidato, ele goza de uma prerrogativa política clara.

Nossa tipologia, portanto, analisa a ação dos moderadores de fóruns de campanha quanto a funções técnicas e políticas. Considerando que tais papéis não são exclusivos, podendo sobrepor-se uns aos outros na atividade de qualquer moderador, buscamos analisar em que medida os moderadores cumpriram as três principais funções acima descritas.

Analisando o fórum de Marina Silva, percebemos que os moderadores cumpriram o papel de gestores, considerando que atuaram no sentido de organizar o fórum, realizaram o processo de agendamento de temas em torno de nove eixos e remeteram os participantes a outros tópicos de acordo com o teor de suas propostas ou questionamentos. No que se refere às funções de árbitro, embora seja claro que os moderadores tenham empreendido tais funções, considerando que o fórum era pré-moderado, não há evidências de censura e, ainda que tenha ocorrido, a partir da análise empreendida, foi possível constatar que alguns comentários e propostas com teor crítico foram publicadas. Os moderadores do fórum de Marina Silva cumpriram, ainda, a função de mediadores, visto que a equipe de conteúdo atuou no sentido de responder ou comentar em nome da candidata cada mensagem que exigisse um posicionamento. Ainda no papel de mediadores, os moderadores sistematizaram as principais contribuições dos internautas para que estas fossem inseridas na segunda versão do programa de governo.

Analisando os rastros digitais deixados pela participação cidadã nos fóruns de discussão do website de Marina Silva, percebemos que o formato 
escolhido de pré-moderação causou descontentamento pela morosidade dos moderadores em liberar algumas mensagens, o que se pôde constatar em mensagens como:

Ontem envie um e-mail perguntando sobre como diminuir a violencia dentro da sala de aula, e disse que ninguem tinha a coragem de vir a publico debater sobre o assunto. Estava certa, pois nem mesmo minha mensagem apareceu na pagina. Ninguem se dignou a responder! Acho que não é um assunto tao importante assim, afinal assuntos mais importantes como reforma agraria, juros, empregos, saude,... não tem seus problemas originados pela precaria educação brasileira (sic).

Fiz uma pergunta nos últimos dias sobre como será financiado o aumento no investimento per capita da educação. Existe algum problema com a pergunta? Se for o caso, poderiam contatar-me por e-mail? Tenho simpatia a candidatura da Marina, e gostaria de ter a resposta... (sic).

Em relação à função de mediação, pôde-se constatar um misto de satisfação com um certo grau de descontentamento. Posts como o abaixo deixaram indícios de insatisfação com a resposta fornecida: "A resposta continua transparecendo não-comprometimento político".

Por outro lado, verificaram-se elogios, expressos em mensagens como: "Obrigada pela resposta, me sinto mais segura agora".

Em relação ao fórum de José Serra, identificamos o papel de gestor, visto que os moderadores organizaram o fórum em torno de temas, destacaram as propostas mais comentadas e elegeram interlocutores para cada eixo temático; os moderadores cumpriram também o papel de mediadores especialmente no vetor internautas $\rightarrow$ candidato, visto que as propostas foram sistematizadas, gerando um relatório de participação, com as principais propostas e perfis dos participantes. No entanto, no sentido contrário, candidato $\rightarrow$ internautas, o papel de mediação ficou aquém da expectativa dos próprios participantes, especialmente no fórum Social Democracia, visto que as perguntas realizadas não foram respondidas, e o único feedback em relação à participação foi verificado quando interlocutores comentaram algumas propostas. A sensação de não estarem sendo lidos gerou frustrações expressas em mensagens como:

Boa tarde,equipe do proposta serra,sujeri algumas medidas e não tive nenhum retorno da equipe,gostaria profundamente de ter uma resposta (sic).

Serra - Porque não escuta seu eleitor??Alooo...Tem alguem ai?? ....Por favor não façam como técnico ignorante de futebol... (sic). 
As pessoas estao fugindo do site, por não ouvi-las, sobre os rumos da campanha é simples assim (sic).

Já no segundo fórum analisado, o de Reforma Agrária, tal fato não ocorreu, visto que um membro da coordenação da campanha publicou duas propostas, o que demonstrou aos participantes que o staff estava presente na discussão.

No tocante à função de árbitro desempenhada pelos moderadores do fórum de discussão do candidato José Serra, pôde-se constatar que os mesmos não cumpriram os critérios objetivos expressos no código de conduta que regia a participação dos internautas. Ao contrário, as regras que orientaram a decisão de excluir ou não uma mensagem foram ambíguas. Enquanto o código de conduta previa a remoção de conteúdos que hostilizassem adversários políticos, fizessem campanha, utilizassem linguagem chula ou palavrões ou promovesse luta política, verificou-se no interior dos fóruns uma grande quantidade de mensagens ofensivas em relação aos adversários (conforme dados apresentados no tópico Respeito Mútuo) e mensagens de campanha que fugiam aos propósitos de debater programa de governo (conforme dados apresentados no tópico Tematização e Conteúdo), que não foi eliminada.

Pelo teor de alguns posts, percebe-se que os moderadores não encaminharam aos remetentes explicações sobre os conteúdos removidos, para que os mesmos pudessem readequar suas mensagens, o que gerou grande insatisfação por parte de alguns internautas:

CENSURA realizada pela EQUIPE SERRA: atrevida, prepotente e grosseira. IRMÃOS E AMIGOS, lamento vos informar que permanecem excluindo "PROPOSTAS" in limine sem qualquer respeito, no mínimo, ao direito ao contraditório. A última exclusão foi "Serra mente? Creio que sim.". Não fala o que sabe de Lula e Dilma. Não considero moralmente suportável este comportamento autoritário e imoral (sic).

A esta mensagem se sucederam outras que demonstravam que as mensagens com o pedido de exclusão também estavam sendo eliminadas:

PERMANECEM CENSURANDO MEU PEDIDO DE EXCLUSÃO.
AGUARDO QUE EXCLUAM ESTA NOVAMENTE.
SOLICITO EXCLUSÃO DO MEU CADASTRO. Não me dirigirei
ao Serra. Penso que ele sequer sabe o que se passa aqui,
todavia, deveria. Pois, não votaria em um candidato a
Presidente que fizesse parte da entourage "do" ou desse
continuidade ao "Não sei e não sabia"; muito menos à
"Direção Executiva" do Proposta Serra. Estes, as palavras que
merecem nã merecem ser ditas;[...] Dirijo-me a vocês, irmãos
e amigos, os que tive a grata satisfação de conhecer aqui e os 
que tive a infelicidade de convidar para abrilhantar este espaço que não nos merece; que confunde participação política voluntária, discussão de "verdades" como subserviência, adesão a, e cessão incondicional de princípios e valores. Provavelmente vivem "da" política e cometem os mais graves pecados mortais de quem dela vive segundo o admirável Max Weber: - "não defender causa alguma e não ter sentimento de responsabilidade.".[...]Não me sentiria bem permanecendo aqui e muito menos traindo a confiança de vocês. Um forte abraço (sic).

\section{Inclusividade, diversidade da participação e reciprocidade do debate}

No sentido de avaliar a inclusividade e diversidade da participação nos fóruns, mensuramos a concentração e o número de mensagens postadas por participante. A literatura indica que o domínio da discussão por poucos usuários pode inibir a participação de outros cidadãos (SAMPAIO, MAIA e MARQUES, 2010). A monopolização do fórum dificulta, ainda, a variedade de opiniões expressas, aspecto que discutiremos no próximo tópico.

Nos fóruns de Marina Silva, os dados agregados dos dois fóruns analisados indicam que, a grande maioria dos participantes (76\%) foi onetimer, ou seja, enviou um único post; apenas um participante encaminhou 5 mensagens e não se verificaram participantes com predominância em qualquer dos dois fóruns analisados, visto que nenhum encaminhou mais de 5 propostas ou comentários. A literatura aponta que o efeito one-timer demonstra que não há monopolização do debate por poucos participantes mas, por outro lado, há pouca reflexividade.

Analisando os dados desagregados referentes aos fóruns do candidato José Serra, notamos que no fórum de Reforma Agrária não houve monopolização da participação, enquanto a análise da concentração de posts por alguns participantes indica que alguns comentadores tiveram grande predominância no fórum temático Social Democracia. Neste último, apenas um participante foi responsável por 64 propostas, excluídos seus comentários às propostas de outros internautas; o segundo maior concentrador de mensagens postou 42 e o terceiro 39 posts. A concentração da participação foi diretamente proporcional ao número de mensagens e inversamente proporcional ao número de participantes: a média de mensagens por pessoa na faixa daqueles que postaram mais de 5 mensagens foi de 12 posts; esta média subiu para 20 quando analisamos o grupo de pessoas que enviaram mais de 10 mensagens, chegando à média de 39 mensagens quando se tratou do grupo que encaminhou mais de 20 mensagens.

Para avaliar a reciprocidade da discussão, buscou-se avaliar se as propostas estavam suscitando debate entre os participantes do fórum ou se, pelo contrário, os internautas postavam suas mensagens sem demonstrar disposição em ler e comentar as propostas de outros participantes. Deste modo, todas as 
propostas que suscitaram algum tipo de debate, comentário ou resposta ou ainda que responderam outra mensagem do fórum foram classificadas como Dialógicas e todas aquelas que não envolveram algum tipo referência, comentário ou resposta foram classificadas como Monológicas. Vale destacar que mesmo algumas mensagens de one-timers foram classificadas como dialógicas quando foram comentadas por outros participantes, porque suscitaram um debate $^{2}$.

Neste quesito, os fóruns do candidato José Serra foram muito mais dialógicos em comparação com os de Marina Silva, pois $30 \%$ das propostas foram comentadas por outros participantes, enquanto no site de Marina Silva poucas propostas foram comentadas ou referenciadas $(n=79)$.

No que se refere à inclusividade, em parte da literatura se enfatiza que o ambiente online possibilita a supressão das hierarquias sociais e das relações de poder que existem offline (WITSCHGE, 2002). Autores como Cardon (2009), entretanto, chamam a atenção para o fato de que atrás do horizonte democrático do "todo-participativo" se reproduz as inegualdades que têm por origem a desigual distribuição dos capitais sócio-culturais da sociedade. Além da divisão digital que separa os que têm acesso à Internet dos que não têm, o meio digital cria outros tipos de exclusão, pois a participação online é mais difícil para aqueles que estão menos familiarizados com a tecnologia (BLATRIX apud WOJCIK, 2008). Mensagens escritas com vocabulário inadequado, muitos erros gramaticais, ortográficos ou de digitação são desacreditadas tanto aos olhos dos representantes políticos quanto dos outros participantes. No entanto, este fato não se verificou nos fóruns analisados. O teor das mensagens mostrou-se decisivo para sua popularidade e não a forma. Verificamos mensagens que, embora apresentando muitos erros do ponto de vista da linguagem, foram bastante populares por manifestarem conteúdos consensuais aos participantes dos fóruns.

\section{Heterogeneidade e debate crítico racional}

Para avaliar o grau de heterogeneidade no interior dos fóruns analisamos se ali se verificou diversidade de opiniões, se as manifestações produziram a sensação de intervenções críticas ou somente adesão e consenso ideológico (DADER e CHENG, 2011).

A literatura temática enfatiza a importância dos fóruns eletrônicos para a troca pública de razões, na medida em que este ambiente mostra-se propício para o surgimento de tensões, tornando mais visíveis os problemas e demandas, o que é relevante para a perspectiva deliberativa de autores como John Dryzek (apud WOJCIK, 2007), Mutz (apud MENDONÇA e PEREIRA,

\footnotetext{
${ }^{2}$ Cabe a ressalva de que neste estudo as mensagens consideradas dialógicas não incluem um grau de reflexividade, visto que tal classificação pressupõe que os participantes estejam analisando criticamente seus próprios valores.
} 
2011), Thompson (apud WOJCIK, 2007), entre outros, para os quais certo grau de desacordo no interior dos fóruns é fundamental para a existência de deliberação. É evidente, no entanto, que tal diversidade de opiniões, que Gutman e Thompson (apud WOJCIK, 2007) denominam de "desentendimentos deliberativos", deve se tornar manifesta em um ambiente respeitoso.

Considerando que os fóruns analisados tratavam-se de dispositivos no interior de websites eleitorais que muito provavelmente iriam atrair o público que tivesse preferência por aquele(a) candidato(a) e suas idéias políticas, trabalhou-se com a hipótese de que no interior dos mesmos não haveria diversidade de opinião. No entanto, embora em pequena quantidade, encontramos a ocorrência de diferentes pontos de vista no interior dos fóruns analisados, como demonstram estas mensagens no fórum do website de Marina Silva:

Acho que para haver igualdade e acabar de vez com o preconceito não basta combater apenas a homofobia, mas a idéia de que casais homossexuais não podem manter uma família com direitos garantidos em lei (incluindo leis de adoção).

Sou a favor que os casais do mesmo sexo tenham direitos em relação a pensão, herança e coisas desse tipo. Sou evangélica e não odeio pessoas assim. Mas me sinto manipulada no contexto em que o homossexualismo fere as leis de Deus. [...] Não posso dizer que esta tudo bem ser homossexual, quando acredito que essa pessoa precisa de apoio espiritual baseado na Bíblia. [...] Sinceramente, não me incluo no caldeirão dos homofóbicos mas, não vou defender o homossexualismo... (sic).

Ou o seguinte diálogo a respeito do aborto no fórum de José Serra:

O.E.N: É fato que no Brasil todo são realizados aborto. Sabemos onde fazer um aborto e até o preço. Devemos parar com a hipocrisia e liberar o aborto, deixando-o como uma opção da mulher. É melhor um aborto do que um filho mal querido, mal tratado ou meliante (sic).

Réplica 1 em relação à proposta de O.E.N:

J.M.S.F: Sua proposta é equivocada. Se o filho é mal querido, pode-se ajudar os pais. Agora, propor a morte para resolver os problemas da vida, é fugir da realidade. O aborto não ajudará a sociedade em nada. abraços a todos (sic).

Tréplica de O.E.N:

REVISTA DEBATES, Porto Alegre, v.6, n.2, p. 173-200, maio-ago. 2012. 
O.E.N: Se você ler o livro Freakonomics, verá uma estatística interessante. $O$ índice de crime no Estado de Nova York (EUA) começou a declinar acentuadamente após 16 anos da liberação do aborto. Ou seja, através do aborto, ou melhor, evitando um nascimento indesejado, os cidadãos de bem passaram a correr menos risco, transformando a sociedade em uma comunidade menos violenta e mais desenvolvida. Deve-se colocar a racionalidade acima da emoção. Emoção só nos ajuda em relacionamentos amorosos, em decisões importantes, só nos induz ao erro (sic).

Réplica 2 em relação à proposta de O.E.N:

R.P.: Você esta na página errada COMPANHEIRO!!!! A Cruz Sagrada seja minha luz. Retira-te satanás, nunca me aconselhes coisas vãs. [...] É mau o que tu me ofereces. Bebe tu mesmo o teu veneno (sic).

Apesar de se verificar uma pequena parcela de propostas não consensuais e algumas manifestações de trocas públicas de argumentos (6\% nos fóruns de Marina Silva e 3,5\% nos de José Serra), notamos que fóruns de discussão de websites de campanha não são ambientes propícios à diversidade de opiniões, tampouco à reflexividade. De acordo com Dahlberg (apud SAMPAIO, MAIA e MARQUES, 2010), quando há "reflexividade" os participantes estão dispostos a avaliar a posição dos outros e revisar a sua posição inicial se persuadidos pela força de perspectivas diversas. Conforme ilustrado, as posições diferentes foram tratadas como anômalas, a partir da invocação de argumentos religiosos. Este perfil é congruente com os achados de Davis (1999) a partir de seu estudo sobre os fóruns Usenet, que foram marcados por ofensas, não tolerância a opiniões distintas e ausência do direito ao contraditório:

The Usenet becomes more than anything a forum for reinforcement. Many political newsgroups are established to present a certain argument. Individuals gravitate to groups agreeing with their own views. Moreover, most of the people who posted on the groups subscribed to other like-minded groups, confirming that the objective is reinforcement of views, not actual exchange. Then, if others attempted to engage in actual exchange, the response often is dismissive. (DAVIS, 1999, p. 162). 


\section{Respeito mútuo e identificação}

A literatura temática enfatiza a importância do respeito mútuo nos debates online, sendo este um dos requisitos elencados por Dahlberg (apud SAMPAIO, MAIA e MARQUES, 2010) para um "Ideal Role Taking". Neste quesito, analisamos o nível de respeito ou desrespeito entre os participantes, a partir da existência ou não de flames e em relação a quem. De acordo com Davis (1999) flaming, o envio de mensagens ofensivas em grupos de discussão, é um termo que não fazia parte do léxico de uma década atrás, no entanto tornou-se um dos principais aspectos abordados quando se analisa a participação online. Como afirma Rosanvallon (2008), a Internet é um meio que possibilita a ampliação da participação; no entanto, não se pode controlar o resultado. A rede eletrônica amplia não apenas a promessa, mas também as patologias associadas à opinião pública. Grande parte da literatura sobre Internet e política teme o perigo dos flames nos fóruns online, qualificando-os como danosos à democracia.

Conforme proposto por Wales et. al. (2010), optamos por enfocar as marcas explícitas de desrespeito e categorizamos as mensagens como respeitosas ou neutras todas aquelas em que não houve desrespeito explícito (Gráfico 1).

Gráfico 1 - Percentual de posts a partir dos indicadores de respeito

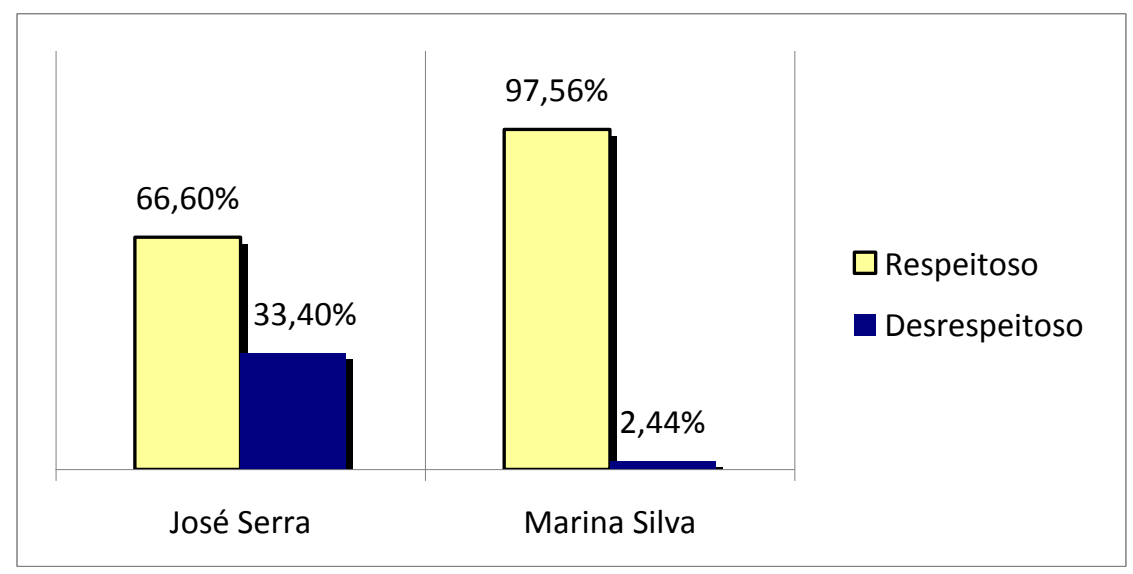

Fonte: Autoria própria.

Classificamos as mensagens sem respeito seguindo a tipologia de Papacharissi (2004) como rudes ou incivis. As mensagens "rudes" (unpolite) são fruto das emoções humanas e, portanto, passíveis de retratação pública e não são, necessariamente, incivis. As mensagens incivis consistem em uma séria ameaça às discussões políticas e à democracia em si, pois ofendem a dignidade. Foram categorizados como Rudes aqueles posts onde o tom era 
ríspido, notava-se animosidade, mas não se atacavam valores democráticos, como este publicado no fórum de Marina Silva:

S.L.B.: Por favor, respondam explicitamente às minhas perguntas, ou apaguem meu comentário anterior. Já estou cansada de demagogias. 1 - A candidata vai lutar para que os LGBTs possam ter EXATAMENTE os mesmo direitos dos héterossexuais? (sic).

As mensagens qualificadas como incivis, por sua vez, foram aquelas nas quais existiam insultos, discursos de preconceito, descrições ofensivas em relação a pessoas ou grupos, ódio ou ataques contra princípios democráticos. Conforme demonstra o Gráfico 1 nos fóruns de Marina Silva houve pouquíssimos indícios de desrespeito, apenas uma mensagem foi classificada como rude em relação à então candidata Dilma Rousseff e 4 em relação aos moderadores do fórum, representantes do staff da campanha.

Os dados evidenciam, no entanto, que uma parcela significativa das mensagens postadas no Proposta Serra foi desrespeitosa (34\%) [gráfico 2], fato que gerou incômodo em alguns participantes, como demonstra este post:

PROPOSTA PARA O PRÓPRIO SITE..PEÇO QUE RETIREM, AS OFENSAS QUE AS PESSOAS DEIXAM NOS COMENTÁRIOS, QUE EU SAIBA, O SITE FOI CRIADO PARA EXPOR IDÉIAS NÃO CRIAR CONFRONTO... (sic).

Gráfico 2 - Mensagens dos fóruns de José Serra de acordo com as marcas de respeito mútuo

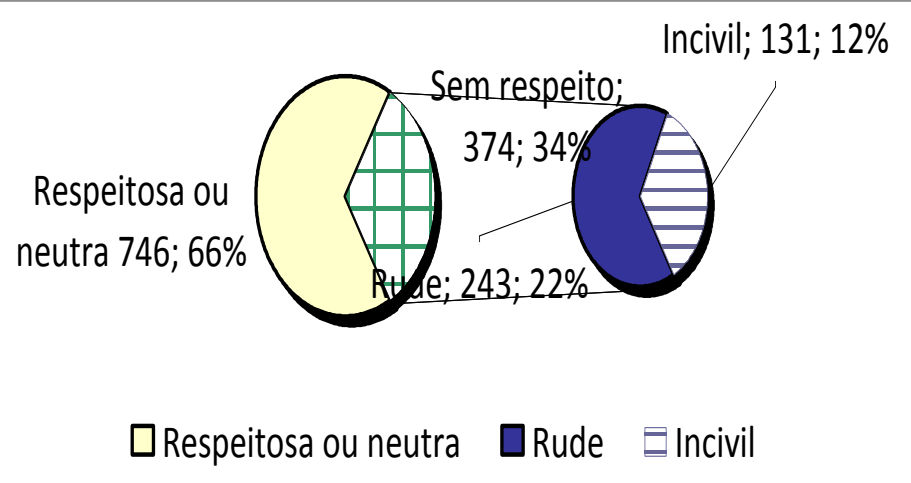

Fonte: Autoria Própria.

Assim como Davis (1999) e Wales et. al. (2010) optamos por uma classificação em relação ao foco de desrespeito e categorizamos as mensagens rudes e incivis em relação a argumentos contidos em posts anteriores, por meio da desconsideração apriorística deles, em relação a 
grupos (organizados ou desorganizados) e instituições ou, finalmente, em relação a terceiros (indivíduos não participantes dos fóruns, como adversários políticos), através do uso de estereótipos e descrições ofensivas, como este post do fórum de Serra, que foi classificado como incivil em relação a grupo:

\title{
[Solução para o MST] É PAREDÂO DE FUZILAMENTO..................SE FOSSE NA CHINA A FAMILIA AINDA TERIA QUE PAGAR A BALA. (sic).
}

Os flames dos fóruns de discussão do website eleitoral de José Serra foram dirigidos majoritariamente a terceiros (Gráfico 3), especialmente aos adversários políticos, a grupos e instituições (PT, MST), em menor medida aos próprios moderadores do fórum, coordenadores da campanha e marqueteiros do José Serra, pela forma de condução da campanha política e, por último, a argumentos de outros participantes dos fóruns contidos em posts anteriores. Os adversários, personificados na figura de Dilma e Lula foram os mais atacados, como ilustra este post incivil em relação a terceiros:

\begin{abstract}
Certamente Lula é um dos fantoches do governo oculto mundial e extremamente vinculado ao projeto SATÂNICO da Nova Ordem (desordem) Mundial (N.O.M.). Como o projeto da N.O.M. é um governo único mundial,ditatorial e fascista, nada de candidatos com histórico humanista (Serra) e sim uma tragédia humana como Dilma Rousseff ( terrorista,ex guerrilheira,assaltante de bancos,participante de atentados políticos,mal resolvida psicológicamente, de formação marxista, cumplice de mortes, autoritária,pavio curto,impulsiva,sem carisma,...). PS: Lula está sob o domínio da fé Baha'i que é a base da Nova Ordem Mundial,na sede do anticristo, a ONU (sic).
\end{abstract}

Gráfico 3 - Destinatários dos flames (mensagens rudes e incivis) dos fóruns de José Serra

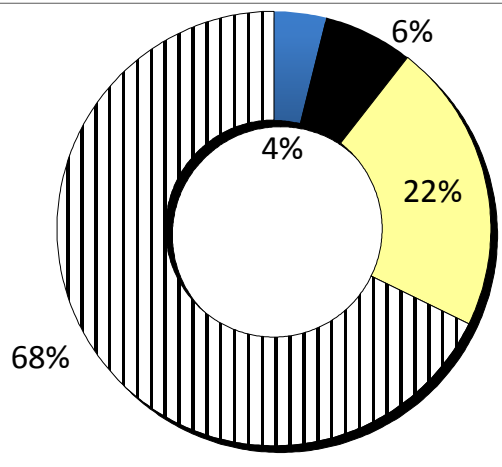

Argumentos

Moderação, Coordenação

$\square$ Grupos ou instituições

$\square$ Terceiros (indivíduos)

Fonte: Autoria Própria. 
Grande parte da literatura aponta que uma das causas para que um ambiente online seja tumultuado é o anonimato dos participantes. O uso de um nome tende a evidenciar que há uma pessoa real (que não se esconde) por trás daquele comentário, que está comprometida com o debate (DAVIS, 2001; WILHELM, apud SAMPAIO; MAIA e MARQUES, 2010). No entanto, não confirmamos este dado em nosso estudo, pois praticamente todos os participantes se identificaram. Realizando um cruzamento dos dados (identificação $X$ flames), constatamos que aqueles que tiveram uma participação anônima por meio de codinomes (O Democrata, Seu Bastião do Burro - nos fóruns de Serra - e Boca, Produção Cultural UFF e Justiça nas Cotas Estudantis - nos fóruns de Marina), não publicaram mensagens desrespeitosas.

\section{Tematização e conteúdo}

Considerando que os espaços digitais analisados visavam debater e realizar aportes aos programas de governo dos candidados, buscamos verificar se estes fóruns cumpriram de fato tal propósito, bem como a natureza das propostas que resultaram desta interação.

Para tanto, analisamos o teor das mensagens, classificando-as em três grandes categorias: (1) propostas ou comentários para fomento ao programa de governo, solicitação de esclarecimentos quanto ao conteúdo programático ou discussão de demandas e anseios dos cidadãos, (2) propostas ou mensagens relacionadas à campanha política, aclamação, endosso ou apoio ao candidato, divulgação da agenda ou repercussão de debates e (3) ataque a adversários, grupos, campanha negativa, ofensas ou estereotipações.

Os dados demonstram (Gráfico 4) que nos fóruns de Marina Silva $82 \%$ das mensagens relacionavam-se a debater propostas de governo, solicitar posicionamentos em relação a temas, expressar anseios e demandas. Foram computadas, ainda, mensagens de aclamação e apoio à candidata e comentários gerais da campanha política e não foram publicadas mensagens de ataque a adversários, somente foi feita uma referência considerada rude à então candidata Dilma Rousseff, quando um participante debateu as condições dos professores. 
Gráfico 4 - Classificação dos posts dos fóruns de Marina Silva quanto ao teor

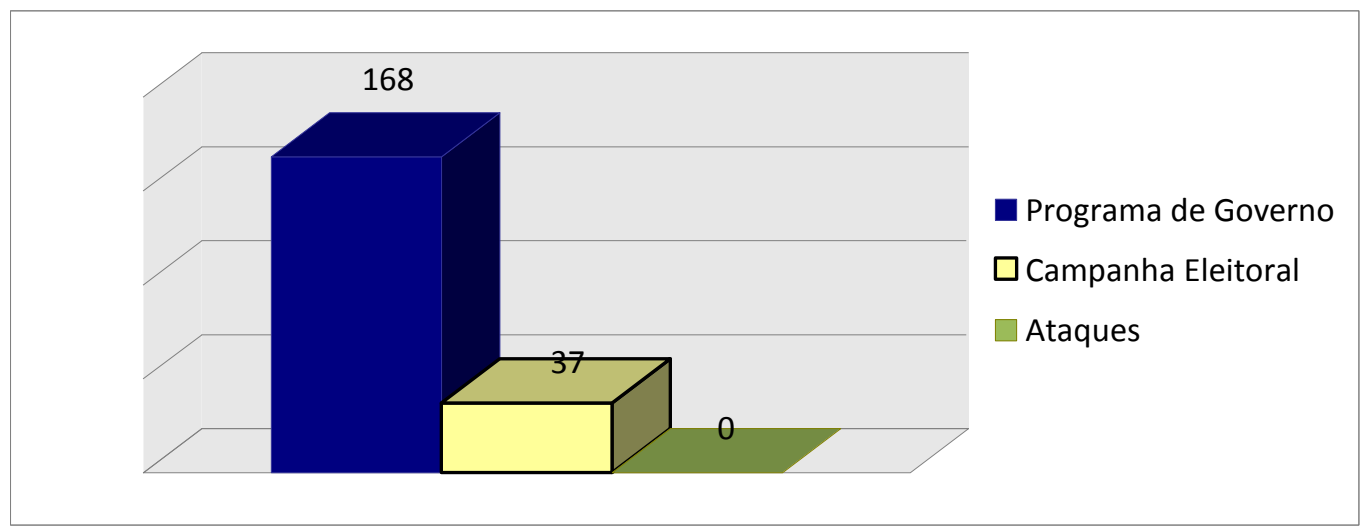

Fonte: Autoria própria.

No entanto, de acordo com os dados agregados, o último objetivo dos participantes dos fóruns de Serra foi debater programa de governo (13\%) e os principais objetivos foram discutir os rumos da campanha (56\%) ou fustigar os adversários (31\%). Este quadro verifica-se em especial no fórum Social Democracia, aquele que contou com o maior número de mensagens $(n=1053)$, de participantes e cujos posts foram os mais comentados (Gráfico $5)$.

Gráfico 5 - Classificação dos posts dos fóruns de José Serra quanto ao teor

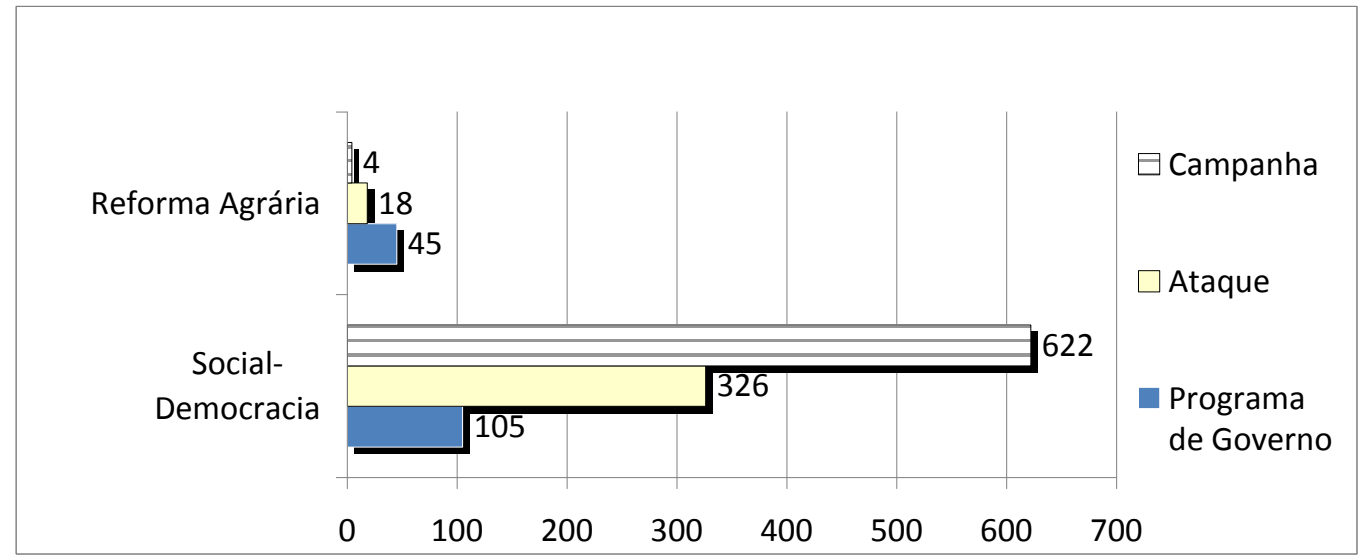

Fonte: Autoria própria.

O cenário modifica-se quando analisamos os dados desagregados (Gráfico 5), que demonstram que no fórum temático com um menor número de participantes, o de Reforma Agrária $(n=67)$, o maior número de posts 
tratava de propostas de governo, embora tenham surgido ali tratamentos fortemente ofensivos e estereotipados em relação a grupos (em especial ao MST), com mensagens que foram qualificadas como incivis.

\section{Considerações finais}

A partir da análise dos websites eleitorais brasileiros foi possível verificar que, embora os partidos e candidatos estejam gradativamente inserindo ferramentas interativas em suas campanhas online, poucos foram os que utilizaram dispositivos que permitem o contato de três vias, ou seja, entre cidadãos e candidatos e de cidadãos entre si. A relutância dos partidos e candidatos em adotar ferramentas interativas em websites eleitorais deve-se à incompatibilidade entre a natureza da Internet e a lógica das campanhas políticas. Campanhas têm por objetivo eleger candidatos e controlar a mensagem é interpretado como crucial a este objetivo (DAVIS, 1999).

Por outro lado, os partidos e candidatos se deram conta de que a nova arquitetura de participação da Web 2.0 é interessante aos propósitos eleitorais, pois propicia uma grande disseminação de mensagens (virality) e possibilita que muitas pessoas colaborem assumindo níveis de responsabilidade muito pequenos (granularity) (CHADWICK, 2008). É, portanto, estratégico beneficiar-se da inteligência coletiva e ao mesmo tempo transmitir um ar de modernidade atrelado a um discurso de participação e democratização.

Deste modo, no intuito de unir ambos os objetivos, ou seja, explorar as potencialidades da Web 2.0 e garantir que o modelo de estratégia de campanha permaneça sendo top-down com um controle firme e centralizado, os partidos políticos e candidatos criaram sua própria abordagem no que se refere à utilização do potencial interativo da Internet, que é um híbrido entre a Web 1.0 e a Web 2.0, que reflete uma utilização da arquitetura de participação, mas um uso muito mais baixo de sua estrutura democrática (LILLEKER e JACKSON, 2008).

No pleito presidencial brasileiro em 2010 somente dois candidatos, José Serra e Marina Silva, disponibilizaram fóruns assincrônicos de discussão. Embora com as limitações aqui referenciadas, tais ferramentas de interação configuraram-se interessantes iniciativas que não se fizeram presentes no website da então candidata Dilma Rousseff, provavelmente por um cálculo estratégico de que em tais espaços poderiam aflorar críticas à sua candidatura e ao governo do qual fez parte.

Os candidatos que disponibilizaram fóruns de discussão o fizeram, no entanto, buscando controlar ao máximo o processo de comunicação: Marina Silva a partir de um formato pré-moderado e José Serra com um fórum onde os moderadores desempenharam uma vigorosa função de arbitragem baseados em critérios ideológicos, onde se notou uma relativização do código de conduta para um filtro interessado das mensagens; a intenção foi controlar a mensagem com propósitos eleitorais e não democráticos. 
Considerando que o objetivo dos fóruns propagados pelos candidatos era debater programa de governo, buscou-se investigar se este foi o resultado dos fóruns, se os mesmos foram marcados pelas condições de debate crítico racional, suas potencialidades e limites.

Os dados demonstram ter sido este, de fato, o propósito do fórum de Marina Silva, cuja coordenação de campanha buscou utilizar o potencial colaborativo da Internet para ampliar as diretrizes de governo da candidata ${ }^{3}$. Grande parte das mensagens relacionava-se a debater propostas de governo e, salvo algumas exceções de aclamação à candidata, o espaço foi ocupado prioritariamente por cidadãos que solicitavam posicionamentos em relação a temas, expressavam anseios e demandas. Para os propósitos democráticos, mostrou-se uma ferramenta importante para que os cidadãos pudessem interpelar a equipe da candidata (pois a mesma não participou diretamente dos fóruns) a respeito de posicionamentos dúbios em especial quanto a temas polêmicos como aborto e união civil entre homossexuais, para um voto mais refletido e informado. Neste quesito, no entanto, as respostas da equipe de conteúdo permaneceram na estratégia de equilibrar a candidatura de Marina Silva entre sua posição religiosa e sua trajetória de militante identificada com as bandeiras das minorias, advogando plebiscitos para discutir temas controversos como subterfúgio para não se indispor com os dois públicos.

Em termos gerais, o fórum de Serra mostrou-se mais como um comitê online de campanha eleitoral do que como um espaço que serviu aos propósitos de debater propostas de governo, pois ali os participantes realizaram fundamentalmente sugestões e comentários para a campanha de José Serra e exploraram o espaço como arena de propaganda negativa, com acusações e campanha difamatória contra os adversários. A estratégia do partido e staff da candidatura de Serra na utilização do espaço foi explorar o potencial viral da Internet para disseminar campanha negativa contra a candidata situacionista, visto que o fórum estava ligado às redes sociais, bem como apropriar-se do conceito colaborativo da Web 2.0 e beneficiar-se da inteligência coletiva como ferramenta de campanha. Por exemplo, verificou-se que neste espaço e a partir da intervenção de uma internauta foi debatida a proposta do salário mínimo em R\$600,00 "L.A: TEMOS QUE URGENTEMENTE COMEÇAR A PROMETER. O SALARIO MINIMO DA DILMA EM 2011 SWERÁ DE 538. QUE TAL SERRA PROMETER ARREDONDAR PARA 600? (sic)".

O Proposta Serra foi, tipicamente, um fórum de aclamação, ataque e reforço, "pregando aos já convertidos" (NORRIS, 2003) visto que a imensa

\footnotetext{
3 Não obstante, não se pode afirmar se tais fóruns foram eficazes ou possibilitaram, de fato, empowerment social, pois não investigamos aqui se tais discussões foram efetivamente incorporadas aos programas de governo dos candidatos (apesar de existir uma segunda versão do programa de governo de Marina Silva aparentemente com incorporações). Tampouco existiam regras claras ou explícitas a esse respeito nos fóruns o que sugere, portanto, que se manteve o gatekeeping padrão, onde os padrões de seleção de propostas seguiram os critérios de conveniência política.
} 
maioria das mensagens seguia uma linha opinativa praticamente consensual e as opiniões dissidentes não eram bem aceitas.

Em que pese a importância da heterogeneidade de argumentos para a democracia, a tendência geral de grupos de discussão é exercer um papel de reforço; a própria lógica das comunidades virtuais é reunir pessoas com valores, interesses e preocupações semelhantes (DAVIS, 1999). A nosso ver, este argumento é especialmente válido em relação a fóruns de campanha, se aplicando muito mais nestes espaços do que em fóruns governamentais deliberativos de políticas públicas.

No que se refere à qualidade dos debates online, ressaltamos a importância que o processo de moderação tem para assegurar seu bom funcionamento e para que se cumpram seus propósitos democráticos. No que se refere ao registro de ofensas, verificamos que papel preponderante foi exercido pela moderação no sentido de evitar ou não a ocorrência de flames. No caso do fórum de Marina Silva, a pré-moderação foi, possivelmente, fator decisivo para a quase inexistência de mensagens rudes e a quantidade nula de incivis que, se existiram, não foram publicadas. Por outro lado, a conivência dos moderadores com os primeiros flames direcionados aos adversários nos fóruns de Serra ditou o tom agressivo e hostil no interior dos mesmos, criando um efeito bola de neve, pois é mais fácil ser respeitoso em um ambiente harmonioso do que em um tumultuado (flamewars).

Pode-se constatar, portanto, como as virtudes políticas da Internet estão imbricadas com armadilhas democráticas (CARDON, 2009), pois a rede eletrônica é um meio que não condiciona imediatamente transformações mais amplas no conjunto da sociedade e no modus operandi da política.

Consideramos, no entanto, que tais iniciativas de criar plataformas abertas para o debate são importantes para aumentar a conexão entre cidadãos e o sistema político, fazendo com que os partidos e candidatos tornem-se a si próprios e as suas propostas mais acessíveis ao eleitor, bem como permitir que demandas e anseios civis se façam manifestos. Mas é necessário que ambos, candidatos e sociedade, aprendam a usar as oportunidades fornecidas pelos novos canais de informação e comunicação no sentido de aprimorar a democracia, para que não se verifiquem muitas pautas de cibermarketing com poucos signos de ciberdemocracia (DADER et. al., 2011).

Sylvia Iasulaitis é Doutora pela Universidade Federal de São Carlos - UFSCar, Programa de Pós-Graduação em Ciência Política.

E-mail: sylviaiasulaitis@yahoo.com

\section{Referências}

ANDUIZA, Eva. Internet, campañas electorales y ciudadanos: el estado de la cuestión. Quaderns del CAC, Cataluña, n. 33, p. 5-12, dez. 2009. 
BÄCHTIGER, André; SHIKANO, Susumu; PEDRINI, Seraina.; RYSER, Mirjam. Measuring Deliberation 2.0: Standards, Discourse Types, and Sequenzialization. In: ECPR General Conference, Potsdam, 2009.

BENTIVEGNA, Sara. Hablar de política en la Red: los newgroups políticos. Cuadernos de Información y Comunicación - Ciberdemocracia, Madrid, n. 6, p. $87-106,2001$.

CARDON, Dominique. Virtudes democráticas da Internet. In: Fórum Reinventar a democracia, Genebra, 2009.

CARLSON, Tom; DJUPSUND, Goran. Old Wine in New Bottles?: The 1999 Finnish Election Campaign on the Internet. Harvard International Journal of Press/Politics, New York, v. 6, n. 68, p. 68-87, jan. 2001.

CHADWICK, Andrew. Web 2.0: New challenges for the study of e-democracy in an era of informational exuberance. Journal of Law and Policy for the Information Society, Colombus, v. 5, n. 1, p. 9-41, 2008.

COLEMAN, Stephen; GOTZE, John. Bowling Together: online public engagement in policy deliberation. London: Hansard Society, 2001.

DADER, José Luis; CHENG, Lifen. Análisis cuantitativo y cualitativo de las web de partidos. In: SAMPEDRO, Victor S. (Org.). Cibercampaña. Cauces y diques para la participación. Madrid: Complutense, 2011. p. 129-143.

DAHLBERG, Lincoln. Democracy via Cyberspace: Mapping the Rhetorics and Practices of Three Prominent Camps. New Media Society, Chicago, v. 3, n. 2, p. 157-177, 2001.

DAVIS, Richard. The web of politics: the internet's impact on the American political system. Oxford: Oxford University Press, 1999.

- Tecnologias de la comunicación y democracia: El factor Internet. Cuadernos de Información y Comunicación - Ciberdemocracia, Madrid, n. 6, p. 9-32, 2001.

GIBSON; Rachel; RÖMELLE, Andrea. Political Communication. In: CARAMANI, Daniele (Ed.). Comparative Politics. Oxford: Oxford University Press, 2007. p. 473-492.

GIBSON, Rachel K.; WARD, Stephen. U.K. Political Parties and the Internet: "Politics as Usual" in the New Media? Harvard International Journal of Press/Politics, New York, v. 3, n. 3, p. 14-38, jun. 1998. 
A proposed methodology for studying the function and effectiveness of party and candidate web sites. Social Science Computer Review, New York, v. 18, n. 3 , p. 301-319, 2000.

GRÖNLUND, Åke; ROSE, Jeremy; AVDIC, Anders; HEDSTRÖM, Karin (Orgs). Understanding e-Participation. Contemporary PhD e-Participation research in Europe. Örebro: University Library, 2007.

HINE, Cristhine. Etnografía virtual. Barcelona: Editorial UOC, 2004.

HOWARD, Philip. Network Ethnography and the Hypermedia Organization: new media, new organizations, new methods. New Media \& Society, London/Thousand Oaks/New Delhi, v. 4, n. 4, p. 550-574, dec. 2002.

LANDTSHEER, Christ'l; KRASNOBOKA, Natalya; NEUNER, Conny. La facilidad de utilización de las "web sites" de partidos políticos. Estudio de algunos países de Europa del este y Occidental. Cuadernos de Información y Comunicación - Ciberdemocracia, Madrid, n. 6, p. 107-140, 2001.

LÉVY, Pierre. Cibercultura. São Paulo: Ed. 34, 1999.

LILLEKER, Darren; JACKSON, Nigel. Politicians and Web 2.0: the current bandwagon or changing the mindset? In: Web 2.0: An International Conference, Royal Holloway, Egham, 2008.

MARGOLIS, Michael; RESNICK, David. Politics as Usual: The cyberspace "revolution". Thousand Oaks: Sage, 2000.

MENDONÇA, Ricardo F.; PEREIRA, Marcus A. Democracia digital e deliberação online: um estudo de caso sobre o VotenaWeb. In: Congresso LatinoAmericano de Opinião Pública WAPOR, 4., Belo Horizonte, 2011.

NEWELL, James L. Italian Political Parties on the Web. Harvard International Journal of Press/Politics, New York, v. 6, n. 4, p. 60-87, set. 2001.

NORRIS, Pippa. Preaching to the converted? Pluralism, Participation and Party Websites. Party Politics, New York, v. 9, n. 1, p. 21-45, 2003.

O'REILLY, Tim; BATTELLE, John. Web Squared: Web 2.0 Five Years O. 2009. Disponível em: <http://assets.en.oreilly.com/1/event/28/web2009_websquar ed-whitepaper.pdf>. Acesso em: 20 out. 2011. 
PAPACHARISSI, Zizi. Democracy online: civility, politeness, and the democratic potential of online political discussion groups. New Media and Society, Chicago, v. 6, n. 2, p. 259-283, 2004.

ROSANVALLON, Pierre. Counter-Democracy. Politics in an Age of Distrust. New York: Cambridge University Press, 2008.

SADOW, James D. A Uses and Gratifications Theory of Internet Campaigning. In: American Political Science Association, 18., Washington, D.C., 2000.

SAMPAIO, Rafael C.; FOOT, Kirsten. The Web as an Object of Study. New Media Society, Chicago, v. 6, n. 1, p. 114-122, fev. 2004.

SAMPAIO, Rafael C.; MAIA, Rousiley Celi M.; MARQUES, Francisco Paulo A. Participação e deliberação na internet: um estudo de caso do Orçamento Participativo Digital de Belo Horizonte. Opinião Pública, Campinas, v. 16, n. 2, nov. 2010.

SCHNEIDER, Steven. Expanding the public sphere through computermediated communication: political discussion about abortion in a Usenet newsgroup. 1997. 189 f. Tese (Doutorado em Filosofia e Ciência Política) Massachusetts Institute of Technology, Cambridge, 1997.

SCHWEITZER, Eva J. Election Campaigning Online: German Party Websites in the 2002 National Elections. European Journal of Communication, v. 20, n. 3, p. 327-351, set. 2005.

STEENBERGEN, Marco; BÄCHTIGER, André; SPÖRNDLI， Markus; STEINER, Jürg. Measuring deliberation: a discourse quality index. Comparative European Politics, Houndmills, v. 1, n. 1, p. 21-48, mar. 2003.

STROMER-GALLEY, Jennifer. On-line interaction and why candidates avoid it. Journal of Communication, Los Angeles, v. 50, n. 4, p. 111-132, dec. 2000.

- Measuring Deliberation's Content: A Coding Scheme. Journal of Public Deliberation, Los Angeles, v. 3, n. 1, p. 1-35, jan. 2007.

SUDWEEKS, Fay; SIMOFF, Simeon. Complementary Explorative Data Analysis: The reconciliation of quantitative and qualitative principles. In: JONES, Steve (Org.). Doing internet research: critical issues and methods for examining the net. Thousand Oaks: SAGE, 1999. p. 29-56.

VACCARI, Cristian. From the air to the ground: the Internet in the 2004 US presidential campaign. New Media Society, Chicago, v. 10, n. 4, p. 647-665, fev. 2008. 
VELASCO, Honorio. Modelos para el trabajo de campo. In: TELLEZ, Anastásia. (Org.). Técnicas de investigación en Antropología. Experiencias de campo. Elche: Universidad Miguel Hernández, 2002.

WALES, Corine; COTTERILL, Sarah; SMITH, Graham. Do citizens 'deliberate' in on-line discussion forums? Preliminary findings from an internet experiment. In: Political Studies Association Conference, Edinburgh, 2010.

WARD, Stephen. Parties and Election Campaigning Online: A New Era? In: WARD, Stephen; OWEN, Diana; DAVIS, Richard; TARAS, David (Eds.). Making a Difference? The internet and elections in comparative perspective. Lanham, MD: Lexington Books, 2008. p. 1-15.

WITSCHGE, Tamara. Online Deliberation: Possibilities of the Internet for Deliberative Democracy. In: Euricom Colloquium Electronic Networks \& Democratic Engagement, Amsterdam, 2002.

WOJCIK, Stéphanie. How Does eDeliberation work? A Study of French Local Electronic Forums. In: GRÖNLUND, Åke; ROSE, Jeremy; AVDIC, Anders; HEDSTRÖM, Karin (Orgs). Understanding eParticipation. Contemporary PhD eParticipation research in Europe. Örebro: University Library, 2007.

. The Three Key Roles of Moderator in Municipal Online Forums. In: Web 2.0: An International Conference, Egham, 2008.

Websites consultados:

$<$ http://www.propostaserra.com.br>.

$<$ http://www.minhamarina.org.br>.

Texto recebido em 20/10/2011.

Aprovado em 23/06/2012. 